\title{
Effect of cross linked sodium hyaluronate in adhesion reduction within the gynecologic surgical window
}

\author{
Liselotte Mettler
}

Department of Obstetrics and Gynecology, University Hospitals of Schleswig Holstein, Campus Kiel, Kiel, Germany

Email: lmettler@email.uni-kiel.de

Received 14 January 2014; revised 8 February 2014; accepted 16 February 2014

Copyright (C) 2014 Liselotte Mettler. This is an open access article distributed under the Creative Commons Attribution License, which permits unrestricted use, distribution, and reproduction in any medium, provided the original work is properly cited. In accordance of the Creative Commons Attribution License all Copyrights (C) 2014 are reserved for SCIRP and the owner of the intellectual property Liselotte Mettler. All Copyright (C) 2014 are guarded by law and by SCIRP as a guardian.

\section{ABSTRACT}

Objectives: On an International scale the Surgical and Clinical Adhesion Research studies (SCAR) solidified the huge impact adhesions have on our Health Care System and the daily complications occurring at surgical procedures because of adhesions. Study: Retrospective file and chart review of 462 patients undergoing laparoscopic surgery at the Department of Obstetrics and Gynecology, University Hospitals of Schleswig Holstein, Kiel. Scientific background of HyaCorp endogel for adhesion prevention and reduction. Observational study applying HyaCorp endogel in 125 gynecological laparoscopic surgeries for adhesion reduction: Laparoscopic Total and subtotal hysterectomies(LTH, LSH) myomectomies and endometriosis surgeries. Additionally the application in $\mathbf{3 0}$ hysteroscopic surgeries such as polypectomies, intracavitary myomectomies and septum resections are described. Results: $50 \%$ of patients $(P<0.005)$ with chronic pelvic pain had thick fibrous adhesions. HyaCorp endogel perfectly adheres to the tissue surface and the abdominal wall creating an anti adhesion barrier without any side effects. At hysteroscopies the application of 1 - $2 \mathrm{ml}$ into the uterine cavity after intra-cavitary procedures was easily performed through a $2 \mathrm{~mm}$ cannula applicator. Postoperatively only in 2 cases patients had a slight pain over the first week, which did not continue. The gel was perfectly tolerated and showed no side effects. Conclusions and Discussion: Fibrous adhesions between pelvic organs and the pelvic side wall during gynecological surgical procedures with laparoscopy cause severe pain and further burden the task of the laparoscopic surgeon. The attempt to reduce these adhesions by applying the site specific, hyaloronic acid based barrier, HyaCorp endogel' proved to be satisfying and helpful in this purely observational study.

\section{KEYWORDS}

Precise Laparoscopic Surgery; Adhesion

Reduction with HyaCorp Endogel

\section{INTRODUCTION}

Adhesions are primarily defined as:

1) The act or state of adhering.

2) Attachment or devotion; loyalty.

3) Assent or agreement to join.

4) Medicine.

a) A condition in which bodily tissues that are normally separate grow together.

b) A fibrous band of scar tissue that binds together normally separate anatomical structures (Figure 1).

5) Physics: The physical attraction or joining of two substances, especially the macroscopically observable attraction of dissimilar substances.

In the present paper, we assess the impact of adhesions as defined above under numbers 4 and 5 as the most common post-surgical complication. Adhesion formation is influenced by various factors. It starts with a trauma to the peritoneum or any other body site, rapidly fibrin deposition occurs. In peritoneal healing for example there is a balance between fibrin deposition and fibrinolysis. Any impairment of this process leads to increased fibrin deposition, the formation of fibrin strands and stable adhesions may be formed.

The incidence of intraperitoneal adhesions in patients following general abdominal or gynecological surgery ranges from $63 \%$ to $97 \%$ [1,2]. The overall risk of hospital readmission related to adhesions following either laparoscopic or open surgery is similar [3]. Although the majority of patients remain asymptomatic, a considerable 


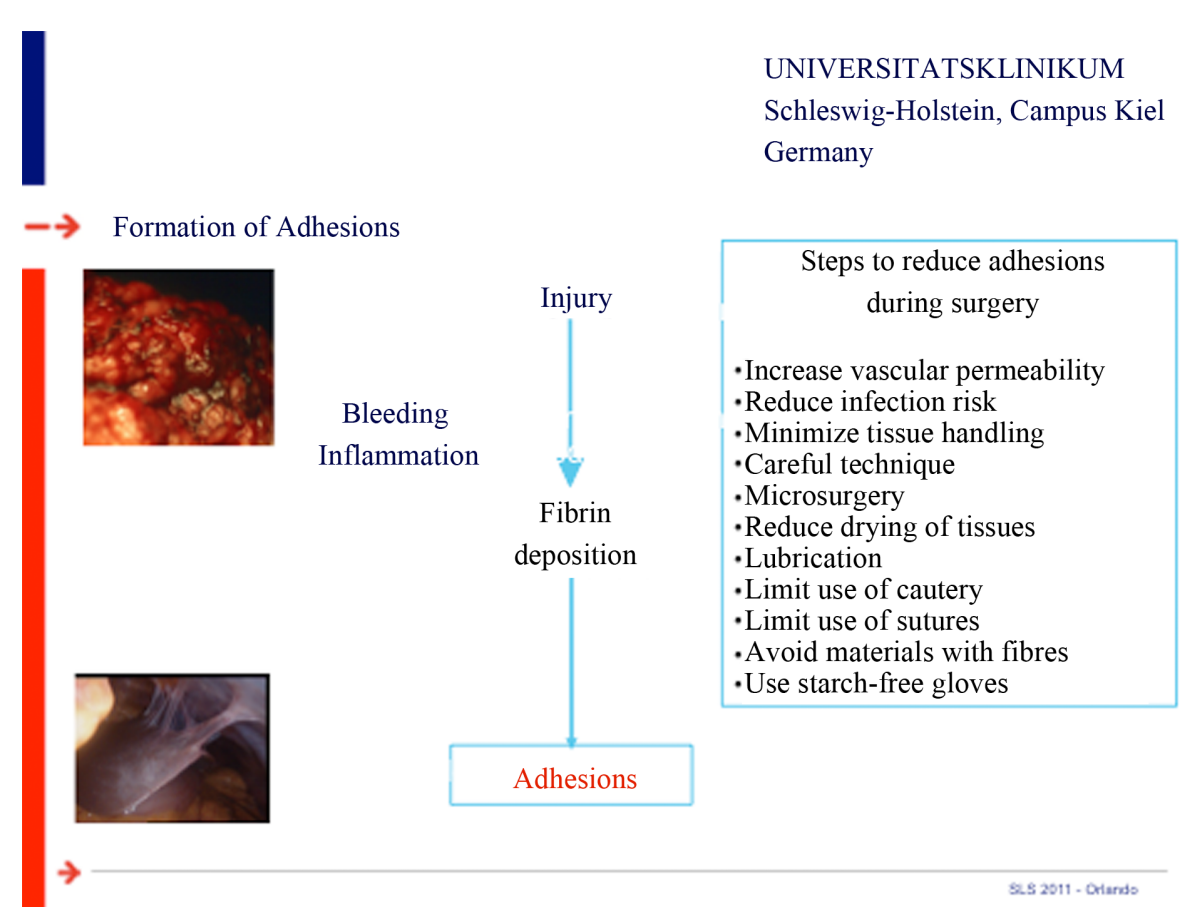

Figure 1. Adhesion formation scheme.

number experience serious complications, including bowel obstruction [4], female secondary infertility [5] and re-operative complications [6]. The presence of adhesions from previous surgery significantly increases the length of time required in subsequent surgical procedures, adversely affecting the workloads of surgical teams [7].

Certain surgical procedures carry a greater risk of adhesion-related complications. Surgical procedures on the ovary and fallopian tube were shown to have the highest risk of adhesion-related readmission $(48.1 \%$ and $41.2 \%$ of women readmitted, respectively) [8]. For laparoscopic myomectomy this increases to 41 in every 100 procedures [9].

In one study, the number of adhesion-related readmissions increased steadily over a ten-year period, with $16 \%$ occurring within the first year after the initial surgical procedure [8]. Some studies have also shown that adhesion-related complications can occur ten years after the initial surgical procedure [2].

More than two thirds of cases of small bowel obstruction are adhesion-related [10]. Moreover, approximately $40 \%$ of chronic pelvic pain cases are related to adhesions [11] and $56 \%$ of repeat surgery is potentially complicated by adhesions [12]. Fertility-related complications are also common with $15 \%$ - $20 \%$ of secondary infertility in women being adhesion-related [5].

Nevertheless, one of the most challenging problems facing the gynecologist is the patient with chronic pelvic pain. It accounts for $10 \%$ of office visits to gynecologists [13]. Laparoscopy is a valuable tool in the evaluation of undiagnosed chronic pelvic pain. It is also extremely valuable in confirming the presence of adhesions which cannot be revealed sonographically.

\section{RETROSPECTIVE EVALUATION OF ADHESIONS IN LAPAROSCOPIC GYNECOLOGICAL SURGERY WITH STATISTICAL EVALUATION}

\subsection{Methods}

A retrospective chart review was conducted at the Kiel School of Gynecological Endoscopy, Germany. All patients $(\mathrm{n}=462)$ who were admitted for diagnostic $(\mathrm{n}=$ $156,33.8 \%)$ or operative laparoscopy $(n=306,66.2 \%)$ were included in this study. The data was collected from the hospital's record system and patients charts. The operative senior consultant had documented all operative reports. The operative reports were reviewed thoroughly.

The patients were categorized according to the reason for admission which included ovarian surgery, pelvic pain, uterine myomectomy, infertility, tubal surgery and laparoscopic hysterectomy. Any other gynecological or surgical procedure was included in the "other surgical procedures" group.

The main procedures performed were documented, as well as the previous history of infertility and past surgical history. Patients with previous surgical history were classified into three groups. The first group included those patients who had previous surgery in an interval of 0 - 5 years and the other two groups, $5-10$ years and $>10$ 
years respectively.

Out of the operation reports the adhesions were classified as thin filmy or thick fibrous adhesions containing blood vessels. Furthermore, the sites of the adhesions were classified according to their presence in the upper abdomen, mid abdomen, pelvis or at multiple sites. Presence of endometriosis and operative complications were also documented.

A senior consultant had carried out all procedures. Patients who were suspected of having adhesions or pelvic pain were managed carefully and Palmer's point was selected as an intraperitoneal entry site using a $5 \mathrm{~mm}$ trocar.

\subsection{Statistics}

The data were analyzed using the SPSS statistical computer program. Comparisons between groups were performed by Pearson Chi-Square tests. Two-tailed tests were used and a $\mathrm{P}$ value $<0.05$ was considered statistically significant.

\subsection{Results}

275 out of 462 patients (59.5\%) were identified as having pelvic or abdominal adhesions (Table 1). The second most frequent reason for admission amongst patients with pelvic pain was the necessity of a diagnostic laparoscopic procedure (30.5\%), which was statistically significant ( $\mathrm{P}<0.0005)$. Other reasons for admission were the necessity for laparoscopic uterine myomectomy (13.5\%), diagnostic laparoscopy for infertility (10.5\%), tubal surgery (6.2\%), laparoscopic hysterectomy (3.3\%) and other gynecological or surgical procedures $(1.8 \%)$.

Regarding the type and site of adhesions, $37.5 \%$ of patients were identified as having thin filmy adhesions (37.9\% in the upper abdominal region, $8.7 \%$ in the mid abdominal region, $27.2 \%$ in the pelvic region and $26.2 \%$ at multiple sites).

Table 1. Reason for admission vs. presence of adhesions among all patients $(\mathrm{n}=462)$.

\begin{tabular}{|c|c|c|c|c|}
\hline \multicolumn{5}{|c|}{ Reason for Admission vs. Presence of Adhesions } \\
\hline & & \multicolumn{2}{|c|}{\begin{tabular}{|l|l} 
Presence of Adhesions \\
\end{tabular}} & \multirow{2}{*}{ Total } \\
\hline & & Yes & No & \\
\hline \multirow{8}{*}{ 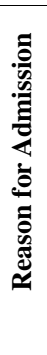 } & Ovarian Surgery & $94(34.2 \%)$ & $61(32.6 \%)$ & 155 (33.5\%) \\
\hline & Pelvic Pain & $84(30.5 \%)^{*}$ & $22(11.8 \%)$ & $106(22.9 \%)$ \\
\hline & Myomectomy & 37 (13.5\%) & $44(23.5 \%)$ & $81(17.5 \%)$ \\
\hline & Infertility & $29(10.5 \%)$ & $21(11.2 \%)$ & $50(10.8 \%)$ \\
\hline & Tubal Surgery & $17(6.2 \%)$ & $21(11.2 \%)$ & $38(8.2 \%)$ \\
\hline & Hysterectomy & $9(3.3 \%)$ & $7(3.7 \%)$ & $16(3.5 \%)$ \\
\hline & Rest of Procedures & $5(1.8 \%)$ & $11(5.9 \%)$ & $16(3.5 \%)$ \\
\hline & Total & $275(100 \%)$ & $187(100 \%)$ & $462(100 \%)$ \\
\hline
\end{tabular}

${ }^{*} \mathrm{P}<0.0005$.
Thick fibrous adhesions containing blood vessels were found in $62.5 \%$ of patients $(19.2 \%$ in the upper abdominal region, $5.8 \%$ in the mid abdominal region, $14.5 \%$ in the pelvic region and $60.5 \%$ at multiple sites, $\mathrm{P}<$ 0.0005) (Figure 2).

Of the 275 patients, 193 (70.2\%) had a previous surgical history, $35.8 \%$ of whom had more than one previous surgery. The other patients had a previous history of one operative procedure which included appendectomy (26.9\%), uterine myomectomy (7.8\%), diagnostic laparoscopy (6.7\%), ovarian surgery (5.7\%), tubal ligation (3.6\%), hysterectomy (2.6\%), ectopic pregnancy $(2.1 \%)$ and other surgical procedures (8.8\%) (Table 2).

Thin

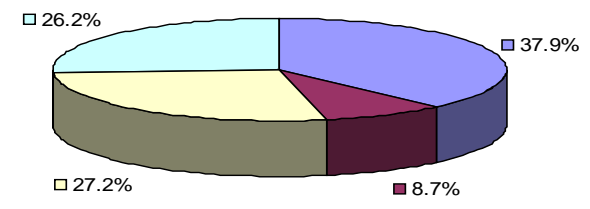

$\square$ Upper Abdomen $\square$ Mid Abdomen $\square$ Pelvis $\square$ Multi Sites

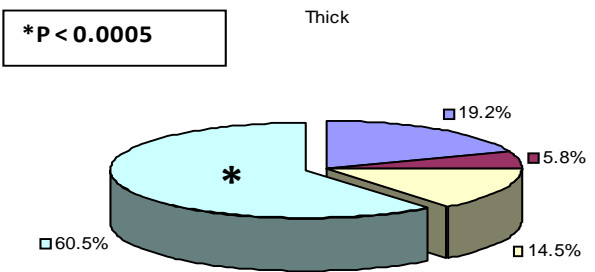

口Upper Abdomen $\square$ Mid Abdomen $\square$ Pelvis $\square$ Multi Sites

Figure 2. Relation between the type and site of adhesions among all patients with adhesions (n = 275).

Table 2. Relation between timing and type of the previous surgery among all patients with adhesions ( $n=193)$.

\begin{tabular}{|c|c|c|c|c|c|}
\hline & \multicolumn{3}{|c|}{ Time Interval of Previous Surgery } & \multirow{2}{*}{ Total } \\
\hline & & 0 - 5 yrs & 5 - 10 yrs & $>10 \mathrm{yrs}$ & \\
\hline \multirow{10}{*}{ 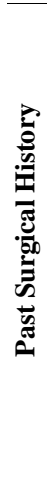 } & $\begin{array}{c}>\text { One Previous } \\
\text { Surgery }\end{array}$ & $9(4.7 \%)$ & $4(2.1 \%)$ & $56(29.0 \%)^{*}$ & $69(35.8 \%)$ \\
\hline & Appendectomy & $2(1.0 \%)$ & $3(1.6 \%)$ & 47 (24.4\%) & $52(26.9 \%)$ \\
\hline & Myomectomy & $7(3.6 \%)$ & $3(1.6 \%)$ & $5(2.6 \%)$ & $15(7.8 \%)$ \\
\hline & $\begin{array}{l}\text { Diagnostic } \\
\text { Laparoscopy }\end{array}$ & 6) & o) & 6) & \%) \\
\hline & Ovarian Surgery & $2(1.0 \%)$ & $2(1.0 \%)$ & $7(3.6 \%)$ & $11(5.7 \%)$ \\
\hline & Tubal Ligation & $1(0.5 \%)$ & $2(1.0 \%)$ & $4(2.1 \%)$ & $7(3.6 \%)$ \\
\hline & Hysterectomy & $1(0.5 \%)$ & $1(0.5 \%)$ & $3(1.6 \%)$ & $5(2.6 \%)$ \\
\hline & $\begin{array}{c}\text { Ectopic } \\
\text { Pregnancy }\end{array}$ & $1(0.5 \%)$ & $0(0.0 \%)$ & $3(1.6 \%)$ & $4(2.1 \%)$ \\
\hline & $\begin{array}{l}\text { Other Surgical } \\
\text { Procedures }\end{array}$ & $1(0.5 \%)$ & $3(1.6 \%)$ & $13(6.7 \%)$ & $17(8.8 \%)$ \\
\hline & Total & $30(15.5 \%$ & $21(10.9 \%)$ & $142(73.6 \%)$ & $193(100 \%)$ \\
\hline
\end{tabular}


Previous surgery was carried out in $15.5 \%$ of patients during an interval of ( 0 - 5 years), in $10.9 \%$ of patients during an interval of (5 - 10 years) and in $73.6 \%$ during an interval of more than ten years. Moreover, the incidence of adhesions was statistically significant among patients with more than one previous surgery, one of them at least during an interval of more than ten years (29.0\%) $(\mathrm{P}<0.0005)$.

Among the 275 patients, only 59 (21.5\%) were identified as having a coexistence of endometriosis. A history of primary infertility and secondary infertility was found in $49(17.8 \%)$ and 9 (3.3\%) of patients, respectively. All 275 patients had intraoperative adhesiolysis; however, only one patient $(0.4 \%)$ had a complication of extensive bleeding.

Further analysis of the patients who were admitted with a history of chronic pelvic pain $\mathrm{n}=106(22.9 \%)$ revealed that 84 (79.2\%) had adhesions (Table 1). Of this subgroup, $19.0 \%$ had thin filmy adhesions: $6.0 \%$ in the upper abdominal region, $2.4 \%$ in the mid abdominal region, $8.3 \%$ in the pelvic region and $2.4 \%$ at multiple sites. Thick fibrous adhesions containing blood vessels were found in $81 \%$ of patients: $9.5 \%$ in the upper abdominal region, $3.5 \%$ in the mid abdominal region, $17.9 \%$ in the pelvic region and $50.0 \%$ at multiple sites (which is statistically significant $\mathrm{P}<0.005$ ) (Figure 3 ).

In regard to the relation between timing and type of previous surgery among patients with chronic pelvic pain, the highest incidence of adhesions was found among patients with more than one previous surgery, one of them at least during an interval of more than ten years (37.3\%); however, this was not statistically significant (Table 3). Finally, only 18 (16.9\%) patients were identified as having a coexistence of endometriosis.

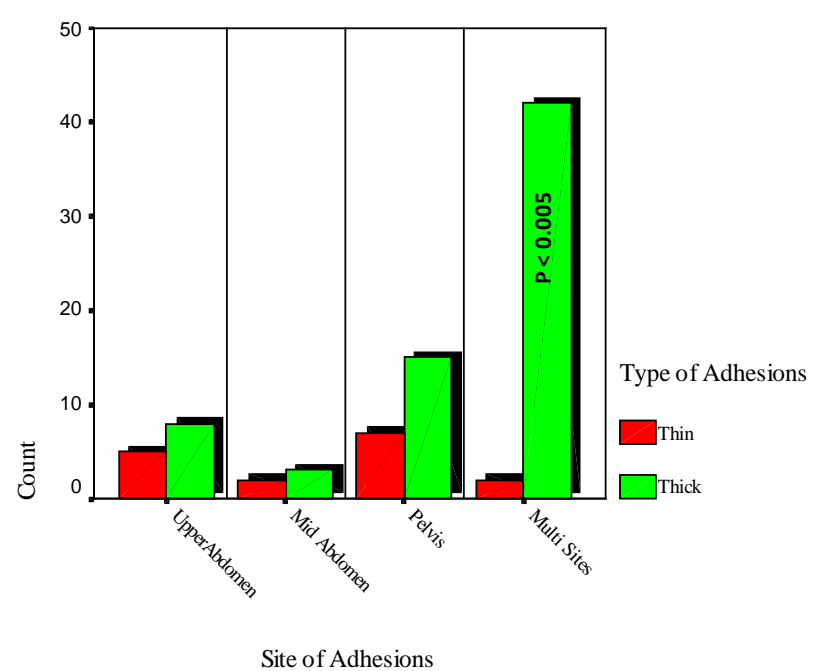

Figure 3. Relation between the type and site of adhesions among patients with chronic pelvic pain.
Table 3. Relation between timing and type of the previous surgery among patients with pelvic pain.

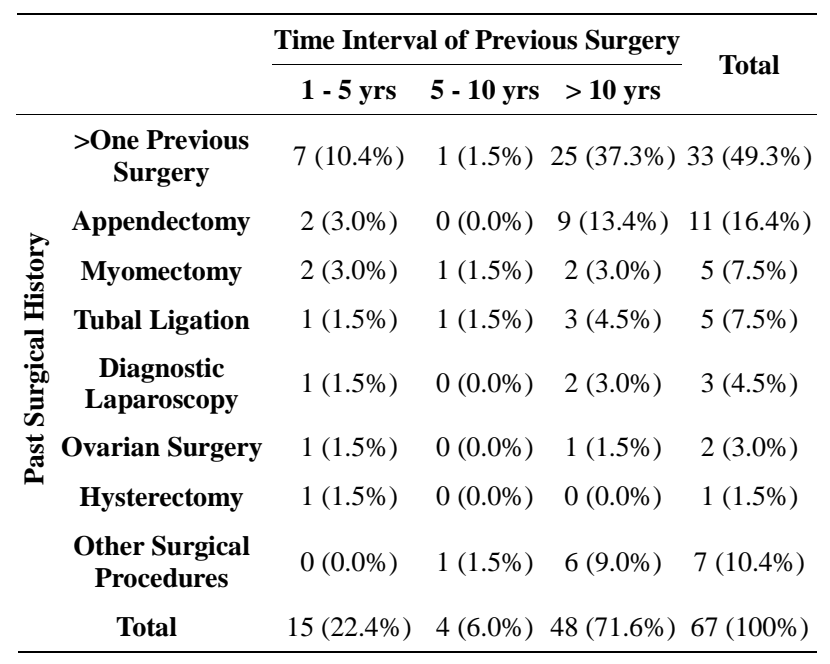

Adhesions can cause significant abdominopelvic pain especially if they are thick fibrous and extend beyond the pelvic sidewall. However, adhesions are not always a source of pain in women with chronic pelvic pain and adhesions. Furthermore, future studies should focus on the clinical use of anti-adhesion agents in the prevention of post-surgical adhesion formation.

\section{SCIENTIFIC BACKGROUND FOR HYA CORP ENDOGEL (BIO SCIENCE, GERMANY)}

The bio absorbable sterile, transparent, high viscous gel is produced by condensation of hyaluronic acid, which is one of the main components of human connective tissue. It adheres to tissue surfaces and to the abdominal wall and is effective as an anti-adhesion barrier substance on the local level. The product specification is detailed in Table 4. The development of Hyacorp Endo Gel is based on a composition of a substance that already exists for treating and filling tissue defects (Hyacorp Body Contouring MLF 1).

On the relatively dry operative site the gel is applied in thick layers out of $10 \mathrm{ml}$ syringes by simple pressure on the piston of the syringe through a special cannular applicator or any cannula available entering through a 5 $\mathrm{mm}$ trocar during the endoscopic surgical procedure (Figure 4). In comparison to other hyaluronic acid containing gels on the market the special cross linked 20 $\mathrm{mg} / \mathrm{ml}$ of hyaluronate makes the essential difference in the effectiveness of this anti adhesion barrier substance.

In a previous study of 25 second-look laparoscopies the incidence of adhesions was $8 \%$ and severity of the adhesions was $16 \%$ but there was no report of the extent of adhesions [14]. In the 10 second-look hysteroscopies no intrauterine adhesions were observed. 
Table 4. Product specification of HyaCorpendogel (qualitative and quantitative composition) reviewed and released by BioScience, date 09.12.2013, Team Pharma.

\begin{tabular}{|c|c|c|}
\hline \multicolumn{3}{|c|}{ Design Name Hylan Gel Indication Prevention of Tissue Adhesion } \\
\hline Trade name & \multicolumn{2}{|c|}{ HyacorpEndo Gel } \\
\hline Ref.-No. & \multicolumn{2}{|c|}{ BS080 } \\
\hline & Specification & Test report \\
\hline appearance & $\begin{array}{l}\text { Clear, transparent } \\
\text { solution }\end{array}$ & PA-048 \\
\hline Viscosity & $27.000-35.000 \mathrm{mPas}$ & PA-038 \\
\hline $\mathrm{pH}$ & $7.0-7.2$ & PA-046 \\
\hline Osmolality & $280-360 \mathrm{mosmol} / \mathrm{kg}$ & PA-026 \\
\hline $\mathrm{NaHA}^{*}$ cross-linked & $20 \mathrm{mg} / \mathrm{ml}$ & PA-039 BDDE-20NM-1 \\
\hline $\mathrm{NaHA}^{*}$ & $10 \mathrm{mg} / \mathrm{ml} / 1$ & PA-013 \\
\hline Cross-linking degree & $35 \%-65 \%$ & PA-051 \\
\hline BDDE & $<0.001 \mathrm{mg} / \mathrm{ml}$ & PA-045 \\
\hline Endotoxine (LAL) & $<0.025 \mathrm{EU} / \mathrm{ml}$ & PA-062 and extern \\
\hline Sterility & sterile & PA-031 \\
\hline Particle size & $200-350 \mu \mathrm{m}$ & PA 047 \\
\hline Volume & $10 \mathrm{ml}$ & PA-034 \\
\hline Syringe & ТорРас & Schott Polymer \\
\hline
\end{tabular}

*Hyaluronic acid ex fermentation. Not animal source!

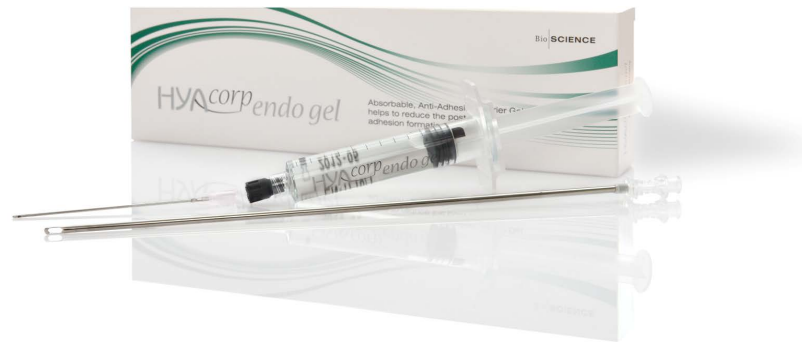

Figure 4. HyaCorp endo gel with applicator in a $10 \mathrm{ml}$ syringe.

\section{OBSERVATIONAL STUDY IN USING HYACORP ENDOGEL FOR ADHESION PROPHYLAXIS IN GYNECOLOGIC ENDOSCOPIC SURGERY}

\subsection{Material and Patients}

170 patients underwent operative laparoscopic or hysteroscopic surgery under general anaesthesia, Trendelenburg position and under $\mathrm{CO}_{2}$ pneumo peritoneum. The preoperative diagnosis was estimated by the history of the patients, the gynecological exam and different imaging technologies such as vaginal ultra sound (VUS), Computer Tomography (CT-scans) or Magnetic Resonance Imaging (MRI). Malignant conditions as well as patients with high-risk medical situations were excluded from the study.

Laparoscopy hysterectomies were performed as total and subtotal procedures with and without adnexectomies. A smaller percentage of patients underwent myomectomy and extended endometriosis surgery. Patients with deep infiltrating endometriosis into the bladder, the rectum and into the parametria were not included. Bipolar coagulation, sutures, morcellators, suction and irrigation was utilized during the surgery.

HyaCorp endogel was applied at the end of every procedure in portions of $10-40 \mathrm{ml}$ through a special 3.5 $\mathrm{mm}$ applicator introduced through the $5 \mathrm{~mm}$ trocar. The ease of applying the gel was judged in a scale of $1-4$.

Of the hysteroscopic surgeries with bipolar electrical resections we observed patients with uterine septum resection, resection of submucous fibroids and polypectomies. As we only used bipolar current the distension medium was saline solution. 45 patients were included into the observational study. After completing the hysteroscopic surgery the cavity was rinsed with saline and through the operative channel of the hysteroscope, the gel was applied using $1-2 \mathrm{ml}$ in total in each case.

\subsection{Results}

All patients tolerated the laparoscopic or hysteroscopic surgery well and were dismissed on the same day or on day 1 or 2 after the surgical intervention. The intraoperative observations of the gel application and the immediate postoperative observations are recorded in Tables 5 and 6.

\section{CONCLUSIONS AND DISCUSSION}

\subsection{Overview on Available Anti Adhesion Agents}

Let us introduce into this discussion first an overview on the most common anti adhesion agents.

Concerning Pharmacological agents the list of options for adhesion prevention is long and these agents may be promising for the future, but no effective pharmacological agent has become available for the human use yet [15]. Konincks and Ussia published in 2010 a nice survey on different agents used in a mouse model including reactive oxygen species scavengers, calcium channel blockers, phospholipids and dexamethason in addition to gentle tissue handling [16].

Non-pharmacological agents are applied to separate the injured tissue from the surrounding organs and the abdominal wall during the time of peritoneal healing, which occurs within the first 7 days after surgery $[17,18]$. Let us first consider the most well-known "Site specific Agents" and compare them with the "broad coverage fluid agents".

Site-specific agents

Mechanical barriers Interceed ${ }^{\circledR}$ (Gynecare, Ethicon, a 
Table 5. Immediate postsurgical site of 125 laparoscopic surgeries andendogel application.

\begin{tabular}{cccccccc}
\hline & $\mathrm{n}$ & Quantity of gel $\mathrm{ml}$ & Ease of applic. 1 - & Pain score 1 - 10 & Susp. infect. +/- & adh. & compl. \\
\hline LTH & 34 & $20-40$ & 1 & 4 & - & none & none \\
LSH & 48 & $10-20$ & $1-2$ & 1 & - & none & 1 \\
Myomect. & 18 & $10-20$ & 1 & 1 & - & none & 1 \\
Endometr. & 25 & $20-40$ & 1 & 2 & - & none \\
$\sum$ & 125 & & & & & \\
\hline
\end{tabular}

Table 6. Surgical site at the hysteroscopic intervention with endogel.

\begin{tabular}{ccccccc}
\hline & $\mathrm{n}$ & Quantity & Ease of application & Pain score & Susp.infect & Complications $(1-10)$ \\
\hline Myomectomy & 22 & $2 \mathrm{ml}$ & Easy & $1-2$ & No & 0 \\
Polypectomy & 16 & $2 \mathrm{ml}$ & Easy & $2-3$ & No & 0 \\
Septum resection & 7 & $1 \mathrm{ml}$ & Easy & $1-2$ & No & 0 \\
Total & 45 & & & & & \\
\hline
\end{tabular}

Johnson \& Johnson Company, Sommerville, NJ, USA):

Interceed $^{\circledR}$ is an oxidized regenerated cellulose membrane placed over a suture or a deperitonealised area. No sutures are required to keep Interceed ${ }^{\circledR}$ in place; slight moistening after positioning a single layer will make it adhere to the injured site, where it is absorbed within 4 weeks [19]. Interceed ${ }^{\circledR}$ has been shown to be effective in various studies, and significantly reduces adhesion formation even in severe endometriosis [20].

Seprafilm $^{\circledR}$ (Genzyme, Cambridge, MA, USA) Seprafilm $^{\circledR}$ : is a hyaluronate-carboxymethyl cellulose membrane, which is placed over a suture or an injured area without stitches and remains in place for 7 days. In contrast to Interceed $^{\circledR}$ no loss of efficacy in the presence of blood has been reported. Several studies have demonstrated the efficacy of Seprafilm ${ }^{\circledR}$ mainly in general surgery, especially bowel surgery [21].

Gel barriers SprayShield/Spray Gel ${ }^{\circledR}$ (Covidien BioSurgery, Waltham, MA, USA): SprayShield ${ }^{\circledR}$ is a synthetic polyethylene glycol solution which is sprayed over the affected area where it remains for approximately 5 7 days. After that period, it is degraded and absorbed. It consists of two components that react immediately on contact with the tissue to form an adherent layer. One of the components contains a blue food colourant, so there is an intraoperative visualization of where SprayShield ${ }^{\circledR}$ was used [17,22,23].

In the case of myomectomy a reduction of adhesion formation was demonstrated for SprayGel ${ }^{\circledR}$ in a multicenter randomized controlled trial.

Intercoat ${ }^{\circledR} /$ Oxiplex/AP (FzioMed, Inc., San Luis Obispo, CA, USA): Intercoat ${ }^{\circledR}$ is an absorbable gel composed of polyethylene oxide and sodium carboxymethyl cellulose. Functioning as a mechanical barrier during the healing process, Intercoat ${ }^{\circledR}$ is applied as a single layer at the end of the procedures.

Hyalobarrier Gel $^{\circledR}$ (Fidia Advanced Biopolymers, Ab- ano Terme, Italy): Hyalobarrier gel is a highly viscous auto-crosslinked hyaluronate used to separate organs and tissues after surgery. The use of hyaluronic acid agents may decrease adhesion formation and prevent the deterioration of pre-existing adhesions [24].

CoSeal $^{\circledR}$ (Baxter Healthcare Corporation, Deerfield, IL, USA): CoSeal ${ }^{\circledR}$ is a resorbable hydrogel consisting of two polyethylene glycol polymer solutions which are mixed together when applied during surgery. The technology is similar to that seen with SprayShield ${ }^{\circledR}$ but in $\mathrm{CoSeal}^{\circledR}$ the polyethylene glycol esters have a different isomer structure. CoSeal ${ }^{\circledR}$ is long available for preventing adhesions in cardiac surgery where its efficacy has already been proved. First researches in women undergoing myomectomy demonstrated safety and efficacy of CoSeal ${ }^{\circledR}$ in abdominopelvic surgery [25].

Broad-coverage fluid agents

Adept $^{\circledR}$ (Icodextrin 4\% solution; Baxter Healthcare, Deerfield, II, USA): Adept ${ }^{\circledR}$ is a clear solution containing icodextrin at a concentration of $4 \%$. Icodextrin is an a 1-4-linked glucose polymer and is responsible for the longer absorption time of Adept ${ }^{\circledR}$ compared to the previously used crystalloid instillates like lactated Ringer`s solution, which is rapidly resorbed by the peritoneum and therefore not suitable for adhesion prevention. At the end of a procedure, $1.000 \mathrm{ml}$ of Adept ${ }^{\circledR}$ is instilled into the abdominal cavity. Instillates separate the injured tissue by hydroflotation and should stay in the abdominal cavity during the first days after surgery. Adept ${ }^{\circledR}$ is absorbed by the lymphatic system within 4 days and is metabolized by alpha-amylase to lower molecular weight oligosaccharides. In a large randomized controlled trial Adept ${ }^{\circledR}$ showed significantly higher adhesion reduction compared with lactated Ringer`s solution. An adverse effect of Adept $^{\circledR}$ is the labial or vulval swelling which mostly resolves after a short period. However, all in all Adep $t^{\circledR}$ is a safe, effective and affordable anti-adhesion 
agent which in a recent study proved to be effective only on the posterior side of the uterus $[26,27]$.

\subsection{General Comparisons}

Postoperative adhesions form after virtually every transperitoneal operation ranging from minimal scarring, present on serosal surface, to dense agglutination of nearly all structures. The most common laparoscopic findings in patients with and without pelvic pain were endometriosis and adhesions. Nevertheless, immunohistologic studies have shown evidence of nerve fibers in adhesions that had been removed from patients with and without pelvic pain [28]. However, in one study, in which laparoscopy was used to evaluate 100 women who consistently reported pelvic pain in the same location for a minimum of six months, adhesions were the most common pathology, accounting for 38\% [29]. In our study adhesions were found in $79.2 \%$ of patients with chronic pelvic pain. Moreover, adhesions with coexistent chronic pelvic pain was the second most frequent reason for admission in our hospital (30.5\%, P < 0.0005) (Table 1).

To accurately describe the extent of peritoneal adhesions during clinical investigations, various scoring systems have been developed. Systematic assessment of adhesions is mandatory to decrease intra observer variation and to provide quantitative data corresponding to their extent and clinical significance [30]. Most scoring systems incorporate adhesion location, vascularity, and type (thickness). Unfortunately, none of the current scoring systems in use have been validated, so that the interpretation of research related to adhesion formation and prevention is difficult. Thus a study that demonstrates a significant change in an adhesion score may not reflect a true clinical difference in the extent of adhesive disease.

Approximately $20 \%$ to $50 \%$ of patients with chronic pain have pelvic adhesions [28,31]. Adhesions that restrict the free movement of pelvic organs have been implicated as a cause of chronic pelvic pain [32,33]. Although there has been no quantitative relationship between the extent of adhesions and either the presence or severity of pain, one study review noted an association between the location of adhesions and the location of pelvic pain [34].We found in our study that 50.0\% (P < 0.005 ) of those patients who had chronic pelvic pain and coexistent adhesions, had thick fibrous adhesions at multiple abdominal and pelvic sites (Figure 3).

Lysis of adhesions has been proposed as the therapeutic modality of choice [32,33], and some investigators report the resolution of chronic pain in individuals after lysis of adhesions whereas others have not noted this effect consistently [32,35,36].

It is better to prevent adhesions forming in the first place rather than treat adhesions once they have occurred. A range of strategies is available to minimize the risk of adhesion formation, including gentle tissue handling, meticulous haemostasis, minimally invasive surgery, constant irrigation and minimal foreign body contact [37, 38]. However, data from some studies indicate that such strategies have had little impact to date [39]. Nevertheless, there are several promising new anti-adhesions products either available or in development. Available clinical data show encouraging results [40]. In cases with chronic pelvic pain and adhesions, in addition to adhesiolysis, if an anti-adhesions agent is safe and cost-effective then its routine use should be supported during surgery, particularly during high-risk procedures.

The present analysis gives an overview on the impact of adhesion found in the treatment of patients in a University Gynecological Department in Germany, which compares well to many other International publications in the field of laparoscopic surgery.

\subsection{Hyaluronic Acid}

The next Generation site specific hyaluronic acid based adhesion barrier gel presented in this observational study with the Crosslinked HyaCorp endogel opens new challenges for adhesion prevention, although no randomized controlled studies are as yet available. The effectivity has been demonstrated in a few animal studies and in 35 second look laparoscopies and hysteroscopies in the field of gynecology [14].

The complex sugar, hyaluronic acid, is detected in all living organisms that retain water and add volume to the tissue. It binds with collagens and elastin and transports important nutrients to these fibres. Unbound hyaluronic acid forms a liquid of highly hydrated polymers.

Hyaluronic acid is a natural complex sugar found throughout all living organisms that retain water and add volume to the tissue. In addition, hyaluronic acid binds with collagen and elastin and transports essential nutrients to these fibres.

In its natural form, unbound hyaluronic acid forms a liquid, made of highly hydrated individual polymers that are metabolized in the body in just 12 hours. Crosslinking of hyaluronic acid refers to a process in which the individual chains of hyaluronic acid are chemically bound (or "cross-linked") together, transforming the liquid hyaluronic acid into a soft solid, or gel. The firmness of the gel depends on the degree of cross-linking of the individual hyaluronic acid chains. The body metabolizes cross-linked hyaluronic acid more slowly, resulting in a longer duration of effect when hyaluronic acid is used therapeutically. Postsurgical adhesions develop following abdominal, gynecological and vaginal surgery as a consequence of abnormal wound healing. Major complications that arise from postoperative adhesions include intestinal obstruction, infertility, chronic pain and loss of bone structure. A wide variety of barrier substances have 
been tested to prevent adhesions after surgery.

Barrier materials are interposed between adjacent surfaces to avoid direct contact; however, unsatisfactory results have often been reported. To obtain low tissue reaction and, consequently, better clinical results, biodegradable barriers are desirable. One particularly promising biopolymer that effectively acts as a barrier is hyaluronic acid (HA). HA has been experimentally shown to reduce postoperative adhesions formation after abdomino-pelvic and orthopedic surgery. The anti-adhesive effects depend on the molecular weight as well as on the concentration of the preparation. However, the results are variable because unmodified HA is subject to rapid degradation and is cleared from the site of administration within hours.

HA modified (cross-linked) with foreign molecules in the form of a resorbable gel has been reported to significantly reduce the incidence and severity of adhesions. In gynecologic surgery no negative effects are reported.

In 2002 and 2003, Beck et al. and Acunzo et al. carried out studies on the prevention of adhesions [41,42]. Di Zerega et al. emphasize this prevention in every publication [43].

Swank et al. could not find a difference in pain score and life quality after laparoscopic adhesiolysis compared to purely diagnostic laparoscopy but the amount of postsurgical rehospitalisation after laparotomy and laparoscopy is evident [44-46]. Therefore, any product without side effects that diminishes postsurgical adhesions is welcome. Hyalobarrier and definitely HYAcorp endo gel are reasonably priced and effective substances that can be easily applied during endoscopic surgery. They are at present tested in many surgical facilities $[47,48]$.

\section{REFERENCES}

[1] Weibel, M.A. and Majno, G. (1973) Peritoneal adhesions and their relation to abdominal surgery. A post-mortem study. American Journal of Surgery, 126, 345-353. http://dx.doi.org/10.1016/S0002-9610(73)80123-0

[2] Menzies, D. and Ellis, H. (1990) Intestinal obstruction from adhesions-How big is the problem? Annals of the Royal College of Surgeons of England, 72, 60-63.

[3] Hawthorn, R.J.S., Lower, A., Clark, D., Knight, A.D. and Crowe, A.M. (2003) Adhesion-related readmissions following gynaecological laparoscopy in Scotland, an epidemiological study of 24,046 patients. Reviews in Gynaecological Practice, 3, 1.

[4] Beck, D.E., Opelka, F.G. and Bailey, R. (1999) Incidence of small bowel obstruction and adhesiolysis after open colorectal and general surgery. Diseases of the Colon \& Rectum, 42, 241-248. http://dx.doi.org/10.1007/BF02237135

[5] Hershlag, A., Diamond, M.P. and Decherney, A.H. (1991) Adhesiolysis. Clinical Obstetrics and Gynecology, 34,
395-402.

http://dx.doi.org/10.1097/00003081-199106000-00023

[6] Holmdahl, I. and Risberg, B. (1997) Adhesions: Prevention and complications in general surgery. European Journal of Surgery, 163, 169-174.

[7] Beck, D.E., Ferguson, M.A., Opelka, F.G., et al. (2000) Effect of previous surgery on abdominal opening time. Diseases of the Colon \& Rectum, 43, 1749-1753. http://dx.doi.org/10.1007/BF02236862

[8] Lower, A.M., Hawthorn, R.J.S., Ellis, H., O’Brien, F., Buchan, S. and Crowe, A.M. (2000) The impact of adhesions on hospital readmissions over ten years after 8849 open gynaecological operations: An assessment from the Surgical and Clinical Adhesions Research Study. BJOG, 107, 855-862. http://dx.doi.org/10.1111/j.1471-0528.2000.tb11083.x

[9] Dubuisson, J.B., Fauconnier, A., Chapron, C., Kreiker, G. and Norgaard, C. (1988) Second look after laparoscopic myomectomy. Human Reproduction, 13, 2102-2106.

[10] Menzies, D. (1993) Postoperative adhesions: Their treatment and relevance in clinical practice. Annals of the Royal College of Surgeons of England, 75, 147-153.

[11] Howard, F.M. (1993) The role of laparoscopy in chronic pelvic pain: Promise and pitfalls. Obstetrical \& Gynecological Survey, 46, 357-387. http://dx.doi.org/10.1097/00006254-199306000-00001

[12] Ellis, H., Moran, B.J., Thompson, J.N., et al. (1999) Adhesion related hospital readmissions after abdominal and pelvic surgery. A retrospective cohort study. Lancet, 353, $1476-1480$. http://dx.doi.org/10.1016/S0140-6736(98)09337-4

[13] Reiter, R.C. (1990) A profile of women with chronic pelvic pain. Clinical Obstetrics and Gynecology, 33, 130136. http://dx.doi.org/10.1097/00003081-199003000-00018

[14] Mettler, L., Sammur, W., Schollmeyer, T. and Alkatout, I. (2013) Cross-linked sodium hyaluronate, an anti-adhesion barrier gel in gynaecological endoscopic surgery. Minimally Invasive Therapy, 22, 260-265. http://dx.doi.org/10.3109/13645706.2012.751034

[15] Ward, B.C. and Panitch, A. (2011) Abdominal adhesions: Current and novel therapies. Journal of Surgical Research, 165, 91-111. http://dx.doi.org/10.1016/j.jss.2009.09.015

[16] Koninckx, P.R. and Ussia, A. (2010) Postoperative adhesion and their prevention. In: Wilde, R.L. and Schmidt, E.H., Eds., State-of-the-Art Prevention of Adhesions in Gynecology, UNI-MED Verlag AG, Bremen, 37-51.

[17] Mettler, L., Audebert, A., Lehmann-Willenbrock, E., Schive-Peterhansl, K. and Jacobs, V.R. (2004) A randomized, prospective, controlled, multicenter clinical trial of a sprayable, site-specific adhesion barrier system in patients undergoing myomectomy. Fertility and Sterility, 82, 398-404. http://dx.doi.org/10.1016/j.fertnstert.2003.12.046

[18] Crowe, A. and Trew, G. (2010) State-of-the-art in adhesion prevention. In: Wilde, R.L. and Schmidt, E.H., Eds., State-of-the-Art Prevention of Adhesions in Gynecology, 
UNI-MED Verlag AG, Bremen, 20-36.

[19] (2011) Usage instructions.

http://www.ethicon360.com/products/gynecare-interceedabsorbable-adhesion-barrier

[20] Sekiba, K. (1992) Use of interceed (TC7) absorbable adhesion barrier to reduce postoperative adhesion reformation in infertility and endometriosis surgery. The obstetrics and gynecology adhesion prevention committee. Obstetrics \& Gynecology, 79, 518-522.

[21] Vrijland, W.W., Tseng, L.N.L., Eijkman, H.J.M., Hop, W.C.J., Jakimowicz, J.J., Leguit, P., Stassen, L.P.S., Swank, D.J., Haverlag, R., Bonjer, J. and Jeekel, H. (2002) Fewer intraperitoneal adhesions with use of hyaluronic acidcarboxymethylcellulose membrane. Annals of Surgery, 235, 193-199.

[22] Ferland, R. and Campbell, P.K. (2009) Pre-clinical evaluation of a next-generation spray adhesion barrier for multiple site adhesion protection. Surgical Technology International, 18, 137-143.

[23] Preventing Adhesions in Gynaecologic Surgery (2009). http://www.orlive.com/covidien/videos/preventing-adhesi ons-in-gynaecologic-surgery

[24] Metwally, M.E., Watson, A., Liford, R. and Vanderkerchove, P. (2006) Fluid and pharmacological agents for adhesion prevention after gynaecological surgery. Cochrane Database of Systematic Reviews. http://dx.doi.org/10.1002/14651858.CD001298.pub3

[25] Mettler, L., Hucke, J., Bojahr, B., Tinneberg, H.R., Leyland, N. and Avelar, R. (2008) A safety and efficacy study of a resorbable hydrogel for reduction of post-operative adhesions following myomectomy. Human Reproduction, 23, 1093-1100. http://dx.doi.org/10.1093/humrep/den080

[26] Brown, C., Luciano, A., Martin, D., Peers, E., Scrimgeour, A. and di Zerega, G. (2007) Adept (icodextrin 4\% solution) reduces adhesions after laparoscopic surgery for adhesiolysis: A double-blind, randomized, controlled study. Fertility and Sterility, 88, 1413-1426. http://dx.doi.org/10.1016/j.fertnstert.2006.12.084

[27] Di Zerega, G.S., Verco, S.J., Young, P., Kettel, M., Kobak, W., Martin, D., Sanfilippo, J., Peers, E.M., Scrimgeour, A. and Brown, C.B. (2002) A randomized, controlled pilot study of the safety and efficacy of $4 \%$ icodextrin solution in the reduction of adhesion following laparoscopic gynaecological surgery. Human Reproduction, 17, 1031-1038. http://dx.doi.org/10.1093/humrep/17.4.1031

[28] Hammoud, A., Gago, L.A. and Diamond, M.P. (2004) Adhesions in patients with chronic pelvic pain: A role for adhesiolysis. Fertility and Sterility, 82, 1483-1491. http://dx.doi.org/10.1016/j.fertnstert.2004.07.948

[29] Kresch, A.J., Seifer, D.B., Sachs, L.B. and Barrese, I. (1984) Laparoscopy in 100 women with chronic pelvic pain. Obstetrics \& Gynecology, 64, 672-674.

[30] Hulka, J.F., Omran, K. and Berger, G.S. (1978) Classification of adnexal adhesions: A proposal and evaluation of its prognostic value. Fertility and Sterility, 30, 661-665.

[31] Cunanan, R.G., Courey, N.G. and Lippes, J. (1983) Laparoscopic findings in patients with pelvic pain. Ameri- can Journal of Obstetrics \& Gynecology, 146, 587-591.

[32] Roseff, S.J. and Murphy, A.A. (1990) Laparoscopy in the diagnosis and therapy of chronic pelvic pain. Clinical Obstetrics and Gynecology, 33, 137-144. http://dx.doi.org/10.1097/00003081-199003000-00019

[33] Rapkin, A.J. (1986) Adhesions and pelvic pain: A retrospective study. Obstetrics \& Gynecology, 68, 13-15.

[34] Stout, A.L. and Steege, J.F. (1991) Relationship of laparoscopic findings to self-report of pelvic pain. American Journal of Obstetrics \& Gynecology, 164, 73-79. http://dx.doi.org/10.1016/0002-9378(91)90630-A

[35] Steege, J.F. and Stout, A.L. (1991) Resolution of chronic pelvic pain after laparoscopic lysis of adhesions. American Journal of Obstetrics \& Gynecology, 165, 278-281. http://dx.doi.org/10.1016/0002-9378(91)90079-7

[36] Peters, A.A.W., Trimbos-Kemper, G.C.M., Admiraal, C. and Trimbos, J.B. (1992) A randomized clinical trial on the benfit of adhesiolysis in patients with intraperitoneal adhesions and chronic pelvic pain. British Journal of $\mathrm{Ob}$ stetrics and Gynaecology, 99, 59-62. http://dx.doi.org/10.1111/j.1471-0528.1992.tb14394.x

[37] Holmdahl, L., Risberg, B., Beck, D.E., Burns, J.W., Chegini, N., di Zerega, G.S. and Ellis, H. (1997) Adhesions: Pathogenesis and prevention-Panel discussion and summary. European Journal of Surgery-Supplements, 557, 56-62.

[38] Ling, F.W., De Cherney, A.H., Diamond, M.P., di Zerega, G.S. and Montz, F.J. (2002) The challenge of pelvic adhesions. In strategies for prevention and management. Educational series on women's health issues. Association of Gynecology and Obstetrics, Corfon.

[39] Lower, A.M., Hawthorn, R.J., Clark, D., Boyd, J.H., Finlayson, A.R., Knight, A.D. and Crowe, A.M. (2004) Adhesions-related readmissions following gynaecological laparoscopy or laparotomy in Scotland: An epidemiological study of 24046 patients. Human Reproduction, 19, 18771885. http://dx.doi.org/10.1093/humrep/deh321

[40] Mettler, L., Audebert, A., Lehmann-Willenbrock, E., Schive, K. and Jacobs, V.R. (2003) Prospective clinical trial of spray gel as a barrier to adhesion formation: An interim analysis. The Journal of the American Association of Gynecologic Laparoscopists, 10, 339-344. http://dx.doi.org/10.1016/S1074-3804(05)60258-7

[41] Acunzo, G., Guida, M., Pellicano, M., Tommaselli, G.A., Di Spiezio Sardo, A., et al. (2003) Effectiveness of autocrosslinked hyaluronic acid gel in the prevention of intrauterine adhesions after hysteroscopic adhesiolysis: A prospective, randomized, controlled study. Human Reproduction, 18, 1918-1921.

http://dx.doi.org/10.1093/humrep/deg368

[42] Beck, D.E., Cohen, Z., Fleshman, J.W., Kaufman, H.S., van Goor, H. and Wolff, B.G. (2003) A prospective, randomized, multicenter, controlled study of the safety of Seprafilm adhesions barrier in abdominopelvic surgery of the intestine. Diseases of the Colon \& Rectum, 46, 13101319. http://dx.doi.org/10.1007/s10350-004-6739-2

[43] Swank, D.J., Swank-Bordewijk, S.C.G., Hop, W.C.J., van Erp, W.F.M., Janssen, I.M.C. and Bonjer, H.J. (2003) 
Laparoscopic adhesiolysis in patients with chronic abdominal pain: A blinded randomized controlled multi-centre trial. Lancet, 361, 1247-1251.

http://dx.doi.org/10.1016/S0140-6736(03)12979-0

[44] Ellis, H., Moran, B.J., Thompson, J.N., Parker, M.C., Wilson, M.S., Menzies, D., et al. (1999) Adhesion-related hospital readmissions after abdominal and pelvic surgery: A retrospective cohort study. Lancet, 353, 1476-1480. http://dx.doi.org/10.1016/S0140-6736(98)09337-4

[45] Mettler, L. (2006) Manual for laparoscopic and hysteroscopic gynecological surgery. Jaypee Brothers Medical Publishers Ltd., 3-184.

[46] Mettler, L., Schollmeyer, T., Kotdawala, P., Zavala, A. and Moharram, A.E. (2002) Laparoscopic surgery and adhesiolysis. Gynaecological Endoscopy, 11, 189-195. http://dx.doi.org/10.1046/j.1365-2508.2002.00530.x

[47] Ruiz, A., Flanagan, C.E. and Masters, K.S. (2013) Differential support of cell adhesion and growth by copolymers of polyurethane with hyaluronic acid. Journal of Biomedical Materials Research, Part A, 101, 2870-2882. http://dx.doi.org/10.1002/jbm.a.34597

[48] Practice Committee of American Society for Reproductive Medicine in Collaboration with Society of Reproductive Surgeons (2013) Pathogenesis, consequences, and control of peritoneal adhesions in gynecologic surgery: A committee opinion. Fertility and Sterility, 99, 1550. http://dx.doi.org/10.1016/j.fertnstert.2013.02.031 